\title{
Effect of whole body hypothermia on inflammation and surfactant function in asphyxiated neonates
}

\begin{abstract}
To the Editor:
Hypothermia has become an evidence-based treatment for neonates with hypoxic-ischaemic encephalopathy (HIE) [1]. The usefulness of hypothermia is due to several mechanisms and among these the reduction in inflammation seems to play a relevant role $[2,3]$. When applied as whole body hypothermia (WBH), cooling may affect other organs as well. Recent data showed better respiratory outcomes and trends towards lower inflammation in WBH-treated preterm lambs [4], suggesting its possible usefulness to reduce lung injury through the modulation of the inflammatory pathway. By contrast, experiments with hibernating animals have shown that temperature induces significant adaptive changes to the surfactant composition and structure [5]. Nevertheless, no data are currently available in humans. Two case reports have recently described an infant [6] and an adult [7] with severe lung injury, whose ventilation had been facilitated by concurrent hypothermia. Since hypothermia is an accepted therapy only for HIE, we designed a preliminary translational study to investigate the effect of WBH on inflammation and surfactant status in neonates with HIE unaffected by any pulmonary injury.
\end{abstract}

Eligible babies were neonates with HIE who required WBH according to TOBY (total body hypothermia trial) criteria [8]. Control babies were normothermic neonates matched for gestational age and SNAPPE-II (Score for Neonatal Acute Physiology and Perinatal Extension-II) score, born within 2 months of the HIE cases and needing intubation for surgical procedures during the first day of life. Both cases and controls had to be free from any pulmonary disease and fulfil the following criteria: 1) normal chest radiograph and auscultation; 2) inspiratory oxygen fraction of 0.21 to achieve arterial oxygen saturation $\geqslant 95 \%$; 3 ) normal amniotic fluid; 4) no signs of infection; and 5) no congenital lung disease or complex malformations.

WBH was started in HIE neonates within the first $6 \mathrm{~h}$ of life and targeted at $33.5^{\circ} \mathrm{C}$ [8] using a whole body servo-controlled mattress, with continuous oesophageal temperature monitoring (Criticool; MTRE Mennen Medical, Feasterville-Trevose, PA, USA). Following our institutional protocol, neonates were mechanically ventilated for $72 \mathrm{~h}$ (until the rewarming), in order to reduce their metabolic demand. Time-cycled, pressure-regulated, assisted-controlled ventilation was set with a tidal volume $\leqslant 5 \mathrm{~mL} \cdot \mathrm{kg}^{-1}$. Blood gas analysis $(\alpha$-stat) was performed from indwelling arterial lines before the onset of WBH (pre-WBH; within the first $6 \mathrm{~h}$ of life) and after 24, 48 and $72 \mathrm{~h}$. Within $3 \mathrm{~h}$ from the blood sampling, nonbronchoscopic bronchoalveolar lavage (BAL) was performed as soon as neonates needed to be suctioned for clinical reasons. BAL was carried out using a standardised technique as previously described [9], in accordance with the advice of the European Respiratory Society Paediatric Task Force [10]. BAL and blood samples were centrifuged $\left(700 \times g, 10 \mathrm{~min}, 4^{\circ} \mathrm{C}\right)$, and serum and supernatant were separated and immediately frozen at $-80^{\circ} \mathrm{C}$. Control babies were sampled only once within $6 \mathrm{~h}$ from intubation. The institutional review board (Dept of Critical Care, University Hospital "A.Gemelli", Rome, Italy) approved the study and informed consent was obtained.

BAL and serum samples were assayed for tumour necrosis factor (TNF)- $\alpha$, interleukin (IL)-1 $\beta$, IL-6, IL-8 and IL-10 using a multiple customised chemiluminescent assay [11], which had a mean coefficient of variation $\leqslant 10 \%$. The serum/BAL urea ratio was used to correct for dilution and obtain epithelial lining fluid (ELF) concentrations [12]. Surfactant function in BAL was studied via fluorescence analysis of adsorption kinetics into the air/liquid interface, as described previously [13]. Results are provided as background-corrected relative fluorescent units. Experiments were performed both at the original neonate's temperature $\left(33.5^{\circ} \mathrm{C}\right)$ and at $37^{\circ} \mathrm{C}$. Fluorescence was continuously assayed and measured at 15,45 and $90 \mathrm{~min}$. All experiments were performed in triplicate, by investigators blinded to the infants' clinical data. Cytokines data were analysed with repeated measures ANOVA. Data from the surfactant study were analysed using multifactorial ANOVA, having surfactant adsorption as the response variable, and the duration of hypothermia at the sample collection (pre-WBH, $24 \mathrm{~h}, 48 \mathrm{~h}$ and $72 \mathrm{~h}$ ) and the time of the experiment at the fluorescence readings $(15 \mathrm{~min}, 45 \mathrm{~min}$ and $90 \mathrm{~min}$ ) as the independent variables. Bonferroni post hoc tests were applied for paired comparisons. 
Significant reductions in IL-6 and IL-8 levels in ELF during WBH were demonstrated (fig. 1a and b). Similarly, serum IL-8 was significantly decreased (mean \pm SE pre-WBH: $194 \pm 115 \mathrm{pg} \cdot \mathrm{mL}^{-1}, 24 \mathrm{~h}$ : $\left.100 \pm 73.5 \mathrm{pg} \cdot \mathrm{mL}^{-1}, 48 \mathrm{~h}: 41 \pm 24.5 \mathrm{pg} \cdot \mathrm{mL}^{-1}, 72 \mathrm{~h}: 42 \pm 242 \mathrm{pg} \cdot \mathrm{mL}^{-1} ; \mathrm{p}=0.003\right)$. No other differences in cytokines levels were observed during WBH, or between cases and controls before the onset of WBH (data not shown). In addition, there was no change in oxygenation index during WBH (data not shown).

The surfactant function assay showed no change after $24 \mathrm{~h}$ of $\mathrm{WBH}$, a significant increase after $48 \mathrm{~h}$ and a significant reduction after $72 \mathrm{~h}$ of hypothermia (fig. 1c). These results were similar and always significant at 15,45 and 90 min fluorescence readings, and at both at $33.5^{\circ} \mathrm{C}$ and $37^{\circ} \mathrm{C}$ (data not shown).

WBH seems to reduce some proinflammatory mediators and have some impact on surfactant function in the ELF of neonates unaffected by any lung injury. These preliminary results are important for fostering new studies investigating more deeply the effect of hypothermia on the lung and its possible applications.

Observational data showed no change in ventilatory parameters and lung mechanics during WBH in neonates mainly without any pulmonary disease [14]. Thus, it is likely that changes in inflammatory and surfactant status might only be clinically evident in diseased lungs: in fact, we did not observe any change in oxygenation or clinical respiratory conditions during WBH. Interestingly, hypothermia modified the inflammatory status in neonatal animal models [4]. Thus, a reduction in inflammatory cytokines could partially explain the positive outcome described in recent case reports of WBH-treated severe lung injury [6, 7].

WBH may also modulate surfactant function, although a time-dependent effect seems to be important. Interestingly, the clinical cases reported to date received a short course of WBH $(\leqslant 48 \mathrm{~h})[6,7]$. In fact, interfacial adsorption is enhanced after $48 \mathrm{~h}$ of hypothermia, suggesting that adaptive mechanisms could have been acting to modulate surfactant behaviour. Our findings subsequently showed impaired adsorption at $72 \mathrm{~h}$, suggesting that any adaptive mechanism cannot be sustained for an unlimited time. Adaptive surfactant changes may include qualitative modifications in phospholipid composition and threedimensional structure. Animals undergoing relatively rapid body temperature fluctuations, for example circadian rhythms in bats or very rapid temperature decays in starving dunnarts, have a surfactant that is less rich in saturated phospholipid species and can cope with a wider temperature range, since its composition is finely tuned through rapid changes in cholesterol [15]. By contrast, animals undergoing long-term seasonal changes of temperature, for example hibernating squirrels, modify their metabolism to produce a totally different surfactant $[5,15]$. Our findings seem to suggest that the phospholipid surfactant composition may not change rapidly enough to adapt to lower temperature long-term. Thus, the improvement in adsorption at $48 \mathrm{~h}$ of WBH could possibly be due to structural reorganisation, which may include the mobilisation of certain species, such as cholesterol, between different surfactant stores. The subsequent decay may indicate that the compensatory mechanisms cannot be sustained long-term.

Moreover, the depth of hypothermia might also be important, as various changes both in surfactant status and cytokine release have been demonstrated at different temperatures in animals [5].
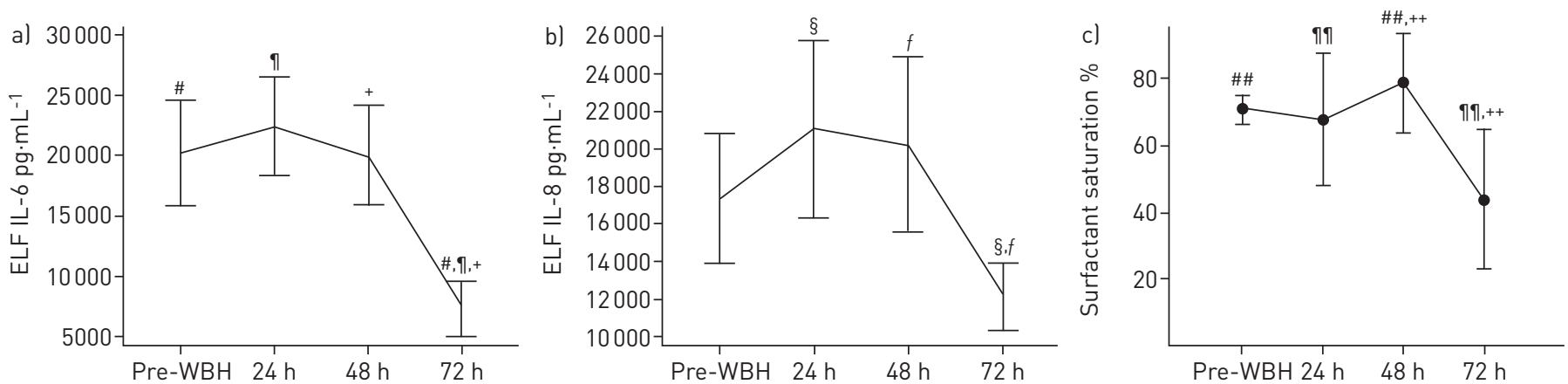

FIGURE 1 Inflammatory mediators and surfactant function in asphyxiated neonates under whole body hypothermia (WBH). Levels of a) interleukin (IL)-6 and b) IL-8 in epithelial lining fluid (ELF). c) Surfactant function presented as the percentage saturation of the interphase upon surfactant adsorption (\% of material upon maximal adsorption) at the end of the experiment $(90 \mathrm{~min})$. Data are presented as mean $\pm \mathrm{SE}$. Raw data were as follows. IL-6: pre-WBH $20.2 \pm 10.5 \mathrm{pg} \cdot \mathrm{mL}^{-1}$, $24 \mathrm{~h} 22.5 \pm 9.8 \mathrm{pg} \cdot \mathrm{mL}^{-1}, 48 \mathrm{~h} 20 \pm 10 \mathrm{pg} \cdot \mathrm{mL}^{-1}, 72 \mathrm{~h} 7.3 \pm 5.6 \mathrm{pg} \cdot \mathrm{mL}^{-1}$; overall $\mathrm{p}=0.005$. IL-8: pre-WBH $17.3 \pm 8.6 \mathrm{pg} \cdot \mathrm{mL}^{-1}, 24 \mathrm{~h} 21 \pm 11.5 \mathrm{pg} \cdot \mathrm{mL}^{-1}, 48 \mathrm{~h}$ $20+11.3 \mathrm{pg} \cdot \mathrm{mL}^{-1}, 72 \mathrm{~h} 12.1+4.4 \mathrm{pg} \cdot \mathrm{mL}^{-1}$; overall $\mathrm{p}=0.046$. Surfactant adsorption: pre-WBH $0.70 \pm 0.04 \mathrm{RFU}, 24 \mathrm{~h} 0.68 \pm 0.19 \mathrm{RFU}, 48 \mathrm{~h} 0.79 \pm 0.15 \mathrm{RFU}, 72 \mathrm{~h}$ $0.44 \pm 0.20 \mathrm{RFU}$; overall $\mathrm{p}<0.001$. RFU: relative fluorescence unit. Symbols indicate significant post-hoc comparisons between different time points following WBH. ${ }^{\#}:$ IL-6 pre-WBH versus $72 \mathrm{~h} \mathrm{p}=0.016 ;{ }^{\circ}$ : IL-6 at $24 \mathrm{~h}$ versus $72 \mathrm{~h} \mathrm{p}=0.008 ;{ }^{+}:$IL-6 at $48 \mathrm{~h}$ versus $72 \mathrm{~h} \mathrm{p}=0.01 ;{ }^{\S}:$ IL- 8 at $24 \mathrm{~h}$ versus $72 \mathrm{~h} \mathrm{p}=0.03 ;{ }^{+}: 48 \mathrm{~h}$ versus $72 \mathrm{~h}$ $\mathrm{p}=0.04 ;^{\# \#}$ : surfactant adsorption pre-WBH versus $48 \mathrm{~h} \mathrm{p}=0.005 ;{ }^{*}$ : surfactant adsorption at $24 \mathrm{~h}$ versus $72 \mathrm{~h} \mathrm{p}=0.019 ;{ }^{++}:$surfactant adsorption at $48 \mathrm{~h}$ versus $72 \mathrm{~h}$ $\mathrm{p}<0.001$. 
Our study is based on a small population and control babies were sampled only once for ethical reasons. However, we must keep in mind that, if ventilation would have had an effect in an extended normothermic control group it would have been towards raising inflammation. These are the first human data on this subject and the next research steps would be clarifying modifications in surfactant composition/structure and investigating the effect of WBH in neonates who are also affected by severe lung injury. This could eventually lead to hypothesises for possible uses of $\mathrm{WBH}$ for critical respiratory conditions.

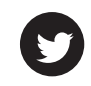

@ERSpublications

Whole body hypothermia might influence inflammation and surfactant status in neonates with no lung disease http://ow.ly/AhEAU

Daniele De Luca ${ }^{1,2,3}$, Sonia Vázquez-Sánchez ${ }^{4}$, Angelo Minucci ${ }^{2}$, Mercedes Echaide ${ }^{4}$, Marco Piastra ${ }^{1}$, Giorgio Conti ${ }^{1}$, Ettore D. Capoluongo ${ }^{2}$ and Jesus Pérez-Gil ${ }^{4}$

${ }^{1}$ Pediatric Intensive Care Unit, Dept of Critical Care, University Hospital “A.Gemelli”, Catholic University of the Sacred Heart, Rome, Italy. ${ }^{2}$ Laboratory of Clinical Molecular Biology, Dept of Laboratory Medicine, University Hospital "A.Gemelli", Catholic University of the Sacred Heart, Rome, Italy. ${ }^{3}$ Division of Pediatrics and Neonatal Critical Care, FAME Dept, South Paris University Hospitals, “A.Beclere" Medical Center - APHP, Paris, France. ${ }^{4}$ Dept of Biochemistry and Molecular Biology, Faculty of Biology, Complutense University, Madrid, Spain.

Correspondence: Daniele De Luca, Service de Pediatrie et Reanimation Neonatale, GHU Paris Sud, Hopital “A.Beclere" APHP, 157 rue de la Porte de Trivaux, 92140 Clamart, Paris, France. E-mail: dm.deluca@icloud.com

Received: May 132014 | Accepted after revision: July 152014 | First published online: Aug 192014

Support statement: This research has been partially supported by grants from the Spanish Ministry of Science and Innovation (BIO2012-30733) and Regional Government of Madrid (S2009MAT-1507) and by institutional funding (2013) of the Dept of Anesthesiology and Critical Care of the Catholic University of the Sacred Heart (Rome, Italy).

Conflict of interest: None declared.

Acknowledgements: The authors are indebted to Antonio Murciano (Complutense University, Madrid, Spain) for his assistance in the statistical analysis on surfactant data and to Massimo Antonelli (Catholic University of the Sacred Heart, Rome, Italy) for his support. The authors are also grateful to the nurses who helped with sample collection.

\section{References}

1 Jacobs SE, Berg M, Hunt R, et al. Cooling for newborns with hypoxic ischaemic encephalopathy. Cochrane Database Syst Rev 2013; 1: CD003311.

2 Han HS, Park J, Kim JH, et al. Molecular and cellular pathways as a target of therapeutic hypothermia: pharmacological aspect. Curr Neuropharmacol 2012; 10: 80-87.

3 Pietrini D, Piastra M, Luca E, et al. Neuroprotection and hypothermia in infants and children. Curr Drug Targets 2012; 13: 925-935.

4 Ball MK, Hillman NH, Kallapur SG, et al. Body temperature effects on lung injury in ventilated preterm lambs. Resuscitation 2010; 81: 749-754.

5 Suri LN, McCaig L, Picardi MV, et al. Adaptation to low body temperature influences pulmonary surfactant composition thereby increasing fluidity while maintaining appropriately ordered membrane structure and surface activity. Biochim Biophys Acta 2012; 1818: 1581-1589.

6 Pietrini D, Pennisi M, Vitale F, et al. Rescue hypothermia for refractory hypercapnia. Eur J Pediatr 2012; 171: $1855-1857$.

7 Duan M, Berra L, Kumar A, et al. Use of hypothermia to allow low-tidal-volume ventilation in a patient with ARDS. Respir Care 2011; 56: 1956-1958.

8 Azzopardi DV, Strohm B, Edwards AD, et al. Moderate hypothermia to treat perinatal asphyxial encephalopathy. N Engl J Med 2009; 361: 1349-1358.

9 De Luca D, Minucci A, Tripodi D, et al. Role of distinct phospholipases A2 and their modulators in meconium aspiration syndrome in human neonates. Intensive Care Med 2011; 37: 1158-1165.

10 de Blic J, Midulla F, Barbato A, et al. Bronchoalveolar lavage in children. ERS Task Force on bronchoalveolar lavage in children. Eur Respir J 2000; 15: 217-231.

11 Cohen JI, Hohman P, Fulton R, et al. Kinetics of serum cytokines after primary or repeat vaccination with the smallpox vaccine. J Infect Dis 2010; 201: 1183-1191.

12 Capoluongo E, Ameglio F, Lulli P, et al. Epithelial lining fluid free IGF-I-to-PAPP-A ratio is associated with bronchopulmonary dysplasia in preterm infants. Am J Physiol Endocrinol Metab 2007; 292: E308-E313.

13 Ravasio A, Cruz A, Pérez-Gil J, et al. High-throughput evaluation of pulmonary surfactant adsorption and surface film formation. J Lipid Res 2008; 49: 2479-2488.

14 Cavallaro G, Filippi L, Cristofori G, et al. Does pulmonary function change during whole-body deep hypothermia? Arch Dis Child Fetal Neonatal Ed 2011; 96: F374-F377.

15 Lang CJ, Postle AD, Orgeig S, et al. Dipalmitoylphosphatidylcholine is not the major surfactant phospholipid species in all mammals. Am J Physiol Regul Integr Comp Physiol 2005; 289: R1426-R1439. 